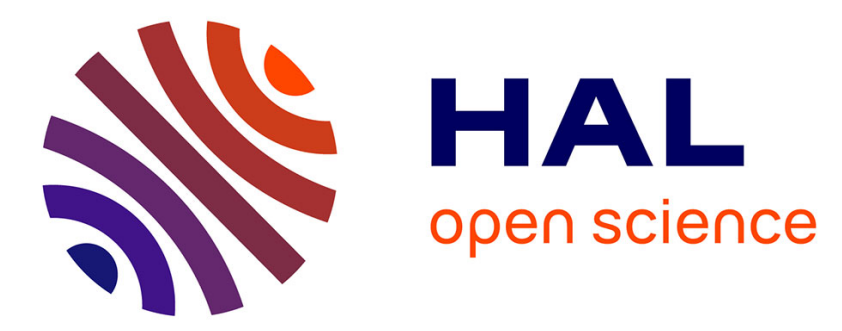

\title{
COORDINATED STUDY OF NEARLY METALLIC POLYACETYLENE : ROLE OF SOLITONS
}

\author{
A. Epstein, H. Rommelmann, R. Bigelow, H. Gibson, D. Hoffman, D. Tanner
}

\section{To cite this version:}

A. Epstein, H. Rommelmann, R. Bigelow, H. Gibson, D. Hoffman, et al.. COORDINATED STUDY OF NEARLY METALLIC POLYACETYLENE : ROLE OF SOLITONS. Journal de Physique Colloques, 1983, 44 (C3), pp.C3-61-C3-68. 10.1051/jphyscol:1983310 . jpa-00222608

\section{HAL Id: jpa-00222608 https://hal.science/jpa-00222608}

Submitted on 1 Jan 1983

HAL is a multi-disciplinary open access archive for the deposit and dissemination of scientific research documents, whether they are published or not. The documents may come from teaching and research institutions in France or abroad, or from public or private research centers.
L'archive ouverte pluridisciplinaire HAL, est destinée au dépôt et à la diffusion de documents scientifiques de niveau recherche, publiés ou non, émanant des établissements d'enseignement et de recherche français ou étrangers, des laboratoires publics ou privés. 


\title{
COORDINATED STUDY OF NEARLY METALLIC POLYACETYLENE : ROLE OF SOLITONS
}

\author{
A.J. Epstein, H. Rommelmann, R. Bigelow, H.W. Gibson, D.M. Hoffman* and \\ D.B. Tanner**
}

Xerox Webster Research Center-W114, Webster, New York 14580, U.S.A.

* Department of Physics, the Ohio State University, Columbus, Ohio 43210, U.S.A. **Department of Physics, University of Filorida, Gainesvilie, Florida 32611 , $U . S . A$.

\begin{abstract}
Rêsumé - Nous présentons ici les résultats d'une étude des propriétés structurales, optiques, magnétiques et de transport de films de cis et trans $(\mathrm{CH}) \mathrm{x}$ dopés lentement avec 1 'iode jusqu'à 1 'état métallique, c'est-à-dire $\left[\mathrm{CH}\left(\mathrm{I}_{3}\right)_{\mathrm{y}}\right]_{\mathrm{x}}^{\prime}, 1,0<\mathrm{y}<5,0$. Les sys-

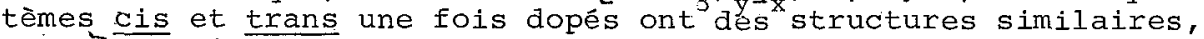
avec êssentiellement des états de solitons chargés. Les résultats sont en accord avec un nouveau mécanisme de transport dans le $(\mathrm{CH})_{x}$, par saut d'amplitude variable parmi des états de type soliton.
\end{abstract}

Abstract - We report here the results of a coordinated study of the structural, optical, magnetic and transport properties of cis and trans polyacetylene slow doped with iodine to nearly metallic levels, i.e., $\left[\mathrm{CH}\left(\mathrm{I}_{3}\right)_{\mathrm{y}}\right]_{\mathrm{x}}, 1.0<\mathrm{y}<5.0$. Cis and trans doped material have similar structure, with essentially all charges going into soliton states. The data are shown to be in agreement with a new mechanism of charge transport in polyacetylene, variable range hopping among soliton-like levels.

\begin{abstract}
Considerable experimental and theoretical interest has focused upon the conducting polymer, polyacetylene, $(\mathrm{CH})_{x}$, and its two isomeric forms cis and trans $/ 1,2 /$. According to the soliton model /3,4/, undoped $(\mathrm{CH})_{x}$ is a semiconductor due to a commensurate Peierls distortion. For the trans isomer the two phases of dimerization are degenerate in energy, hence the formation of solitons is favored in this system. These solitons are either neutral with a spin or charged with no spin. For cis- $(\mathrm{CH})_{x}$ (cis-transoid) a change in phase of dimerization results in the trans-cisoid structure which is not degenerate in energy. Hence other excitations such as bipolarons are favored in this system $/ 5,6 /$. The conductivity, 5 , at room temperature of both isomers increases from nonmetallic levels $\left(10^{-9}\right.$ (ohm $\mathrm{cm})^{-1}$ for cis and $10^{-5} \mathrm{ohm}^{-1} \mathrm{~cm}^{-1}$ for trans) to metallic levels $\left(10^{+2}\right.$ $10^{+3} \mathrm{ohm}^{-1} \mathrm{~cm}^{-1}$ ) upon doping with acceptors such as $\mathrm{I}_{3}$, $\mathrm{AsF}_{5}$ or $\mathrm{ClO}_{4}$ or donors such as Li $/ 7 /$ to levels of 20.06 per polyacetylene carbon atom. Optical $/ 8,9 /$ and structural $/ 10 /$ studies have demonstrated that upon doping the ois isomer evolves to the doped trans isomer configuration. Magnetic susceptibility $(\chi) / 11,12 /$, dc and ac transport /13,14,15/, and optical /16/ and infrared /9/ absorption studies of undoped or lightly doped trans $-(\mathrm{CH})_{\mathrm{x}}$ support the soliton picture $/ 3,4 /$.
\end{abstract}

Samples slowly doped to concentration of 0.01 to $0.05 \mathrm{I}_{3}$ - per carbon of trans- $(\mathrm{CH})_{\mathrm{x}}$ have been shown $/ 11 /$ to have magnetic susceptibility much 
lower than that of the metallic state, $X$ Pauli, yet have high conductivity. Similar results were reported for $A_{s F} 6$ slowly doped trans samples $112,14 /$. This led to the suggestion $/ 17 /$ that unpinned charged solitons determine the transport in the low $x^{\text {Panl }}$ regime. Larger $x$ Pauli were reported for cis-(CH) $\mathrm{x}$ doped with $\mathrm{AsF}_{5}$ to near one percent concentration /18/. On the basis of this and temperature dependent transport data, a model of formation of metallic islands separated by undoped polymer was proposed /18/. However, magnetic /11,12/, optical /16/ and transport /14,15,19/ studies of doped $(\mathrm{CH})_{X}$ have shown that though the dopant distribution may be nonuniform, it is not segregated into metallic islands.

Here we report the results of an extensive series of coordinated measurements of $\left[\mathrm{CH}\left(I_{3}\right)_{y}\right]_{x}$ with $0.01<y<0.05$, in the range where the doped polymer has been reported to have high conductivity with low susceptibility ( $\left.\chi^{\text {SPIN }} \ll X^{\text {Pauli }}\right)$. Structural, optical, magnetic and conductivity and thermopower (S) studies were performed on sections of the same films. The results are inconsistent with clusters of small metal particles. The data show that both cis and trans doped material are very similar with similar structure and all charges, up to the highest levels studied here, $\left(\mathrm{CH}\left(\mathrm{I}_{3}\right)_{0.048}\right)_{\mathrm{x}}$ going into solitonlike states. On the basis of the data presented here, a different mechanism of charge transport is proposed, variable range hopping among soliton levels. The data are shown to be in quantitative agreement with this picture.

Polyacetylene was prepared by the Shirakawa technique /20/. The films are $90 \%$ cyrstalline /10/ and are composed of $500 \AA$ diameter fibrils /21/ The "slow doping" technique /11/ was used to prepare samples. Between experiments, samples were stored in sealed evacuated vessels at $193 \mathrm{~K}$. Pieces of the same films were used for all experiments reported here. The temperature $(T)$ dependent $X$ was measured using a very sensitive Faraday technique from $4 \mathrm{~K}$ to $320 \mathrm{~K} / 11 \%$ The calibration of the apparatus was verified by measurement of an aluminum standard provided by the National Bureau of Standards. Room temperature reflectance measurements $/ 22 /$ were made between 20 and $700 \mathrm{~cm}^{-1}(0.002-0.09 \mathrm{eV})$ using a Michaelson interferometer. A grating monochromator was used for reflectance measurements between 700 and $7000 \mathrm{~cm}^{-1}(0.09-0.9 \mathrm{eV})$. A Kramers-Kronig analysis of the reflectance was performed in order to calculate the frequency dependent conductivity and dielectric function. $S(T)$ and the four-probe $\sigma(T)$ and its electric field (E) dependence were measured during the same run.

The X-ray diffraction study $/ 10 /$ of cis- $(\mathrm{CH})_{x}$ slow doped to $\left(\mathrm{CH}\left(\mathrm{I}_{3}\right)_{y}\right)_{\mathrm{x}}$ with $y=0.033$ and $y=0.048$ yields nearly the identical results as those for trans- $(\mathrm{CH})_{\mathrm{x}}$ slow doped to $\mathrm{y}=0.017$ and $\mathrm{y}=0.042$, in agreement with the earlier optical $/ 9 /$ and transport studies of light doping $(y<0.01)$ of the cis isomer resulting in doped trans. For all iodine doping levels studied, about one-third of the sample volume remains undoped. As a uniform iodine distribution is observed in energy dispersive X-ray analysis $/ 21 /$, these undoped regions are in the centers of the $500 \AA$ diameter fibrils. Three broad $X$-ray reflections are found for $\left[\mathrm{CH}\left(\mathrm{I}_{3}\right)_{y}\right]_{\mathrm{x}}$ corresponding to interplanar spacings of $7.9 \AA, 4.1 \AA$ and $2.9 \AA$, in agreement with a model 123/ of intercalation between polyacetylene planes. The transverse coherence length for the doped $(\mathrm{CH})_{\mathrm{X}}$ is $20 \pm 5 \AA$.

The frequency dependent conductivity obtained by Kramers-Kronig analysis of the reflectance data samples of $\mathrm{y}=0.033,0.042$ and 0.048 is shown in Figure 1 for frequencies up to $7000 \mathrm{~cm}^{-1}$. These doped samples each have a strong absorption centered at $2800-3800 \mathrm{~cm}^{-1}$, with the tail of this absorption extending to zero frequency. The zero frequency conductivity 


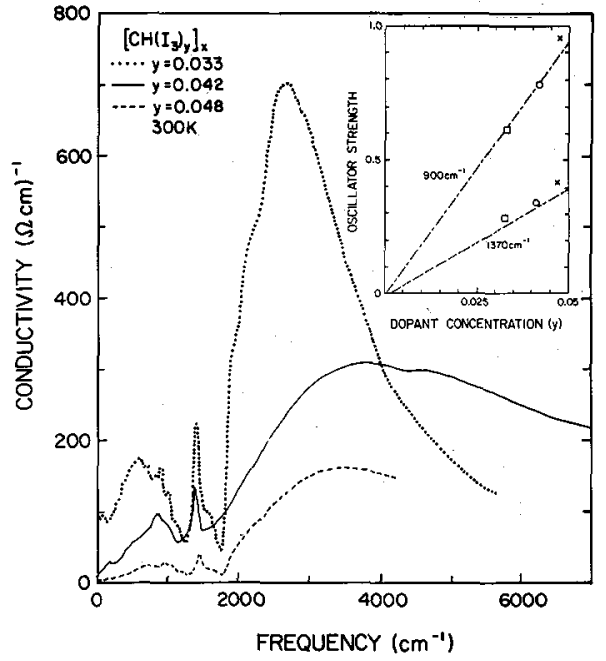

\section{FIGURE 1}

Frequency dependent conductivity of slow doped $\left(\mathrm{CH}\left(\mathrm{I}_{3}\right)_{y}\right)_{x}$.

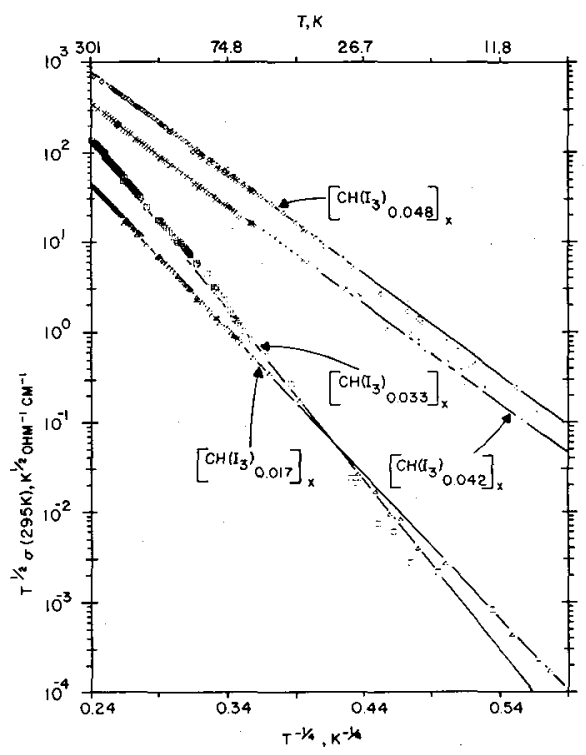

FIGURE 3

$T^{1 / 2} \sigma(T) / \sigma(295 \mathrm{~K})$ versus $T^{-1 / 4}$ for slow doped $\left[\mathrm{CH}\left(\mathrm{I}_{3}\right)_{y}\right]_{x}$.

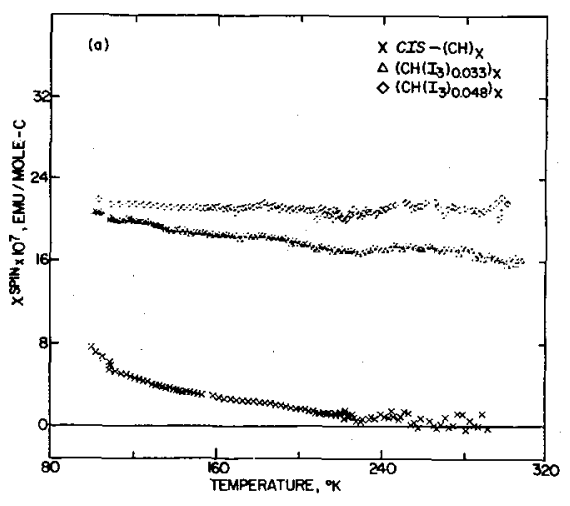

FIGURE 2a

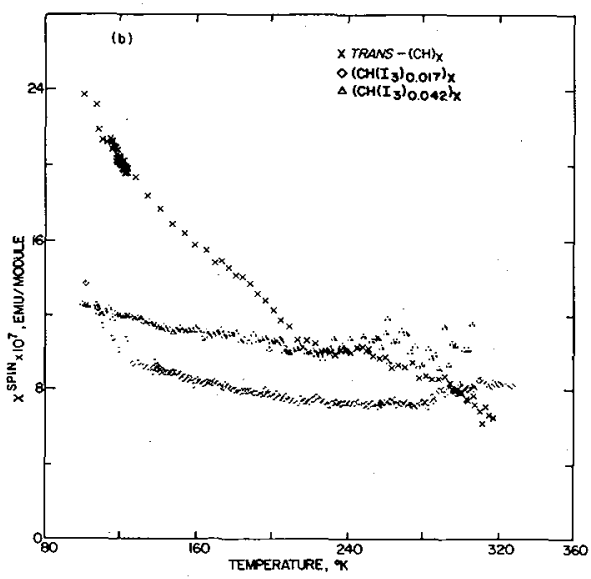

FIGURE 2b

\section{FIGURE 2}

Spin susceptibility versus temperature for (a) $\mathrm{Cis}-(\mathrm{CH})_{\mathrm{C}}$ and iodine doped $\mathrm{Cis}-(\mathrm{CH})_{X}$, and (b) trans- $(\mathrm{CH})_{X}$ and iodine doped trans $-(\mathrm{CH})_{\mathrm{X}}$.

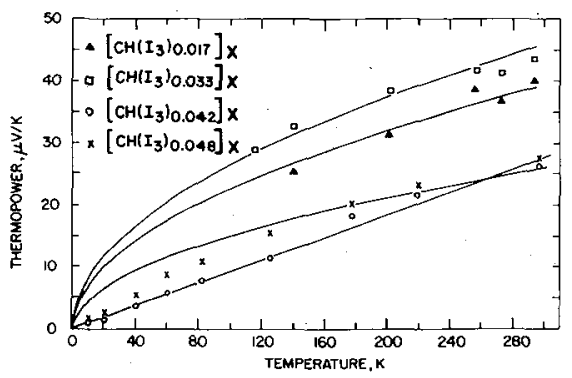

FIGURE 4

Thermopower versus $T$ for $\left[\mathrm{CH}\left(\mathrm{I}_{3}\right)_{y}\right]_{x}$. The solid 7 ines are fits to Eqs. 2 and 3 , see text. 
obtained is approximately 1.0 to.2.0 times the measured room temperature dc conductivity. Extension of $\sigma(\mathrm{f})$ to $20,000 \mathrm{~cm}-1$ for $\mathrm{y}=0.042$ shows that the original interband transition of trans- $(\mathrm{CH})_{x} / 1,11 /$ is no longer observed.

Two strong maxima are observed, a narrow one at $1370 \mathrm{~cm}^{-1}$ and a broader one centered at $900 \mathrm{~cm}^{-1}$. These features are associated with the formation of charged solitons created by chemical doping /24/. The oscillator strength for each mode was calculated after subtracting off the low energy tail of the main absorption at $3000 \mathrm{~cm}^{-1}$. The results are shown in the insert in Figure 1. The data for these nearly metallic samples show the same oscillator strength per $\mathrm{I}_{3}{ }^{-}$as reported 19,24/ for lower doping concentrations. Hence doping with iodine to concentrations of $\mathrm{I}_{3}^{-}$as high as 0.048 results in approximately as many charged solitons even at these high concentrations. This is just below the concentration of 0.07 where 15 carbon unit long solitons will overlap /3,4/.

Assuming excitation from the valence band to soliton levels is the origin of a large part of the strong absorption centered at $3000 \mathrm{~cm}^{-1}$, one can utilize the oscillator strength per soliton and the known doping concentration to determine at what frequency soliton contributions to this strong absorption are exhausted. For each of the three curves shown in Fig. 1 , the oscillator strength for soliton contributions is exhausted before the peak in the absorption. Hence this peak includes contributions of excitations from valence band to soliton levels and valence band to conduction band across a reduced bandgap $/ 11,25 \%$. These results are inconsistent with the expectations of the model /18/ of doping into isolated metallic regions.

The temperature dependent spin susceptibilities ( $X$ SPIN) for the starting cis- $(\mathrm{CH})_{x}$ and $\mathrm{cis}-(\mathrm{CH})_{x}$ doped to $0.033\left(\mathrm{I}_{3}{ }^{-}\right)$and $0.048\left(\mathrm{I}_{3}{ }^{-}\right)$are shown in Figure $2 a$, while the results for trans- $(\mathrm{CH})_{X}$ and the trans- $(\mathrm{CH})_{X}$ doped to $0.017\left(I_{3}\right)$ and $0.042\left(I_{3}^{-}\right)$are shown in Figure $2 \mathrm{~b}$. The core dimagnetism was experimentally established /11/ for $(\mathrm{CH})_{\mathrm{x}}$ and iodine and subtracted from all data. The remaining $\chi^{\mathrm{SPIN}}$ is well represented as a sum of $\chi^{\text {CURIE }}=$ $\mathrm{N}^{\mathrm{C}} \mathrm{g}^{2} \mu_{\mathrm{B}}{ }^{2} / 3 \mathrm{k}_{\mathrm{B}} \mathrm{T}$ and $X^{\text {PAULI }}=2 \mu_{\mathrm{B}}{ }^{2} \mathrm{~N}\left(E_{\mathrm{F}}\right)$. Here $\mu_{B}$ is the Bohr magneton, $k_{B}$ the Boltzmann constant, $N^{c}$ the density of Curie spins and $N\left(E_{F}\right)$ the density of states at the fermi level for both directions of spin, assuming no Coulomb enhancement of $x^{\text {PAULI. }}$

The starting cis material had $\mathrm{N}^{\mathrm{C}}=188 \mathrm{ppm}$ probably as a result of the presence of $10-15$ percent trans in it. The trans sample which was obtained by isomerization in vacuo at $207^{\circ} \mathrm{C}$ for 98 minutes, had $\mathrm{N}^{\mathrm{C}}=583 \mathrm{ppm}$. As was reported $/ 11,12 /$ earlier, $\mathrm{N}^{\mathrm{C}}$ decreases dramatically with doping, in agreement with the soliton mechanism of doping. For the trans starting material, approximately one-third to one-fifth of the Curie spins remain even after doping to 12.5 percent iodine $(y=0.042)$. This is consistent with the X-ray diffraction results /10/ which show about one-third of the trans- $(\mathrm{CH})$ remaining undoped. The highly doped cis- $(\mathrm{CH}) \times$ sample $(y=$ 0.048 ) has no localized Curie spins, though the $X$-ray diffraction studies $/ 10 /$ also showed that the undoped regions of the initially cis film have isomerized to the trans structure. Isomerization at room temperatures (the temperature during doping) probably produces few crosslinks. Hence mobile solitons in the undoped trans regions of the initially cis film would be able to migrate to regions where there are dopants present and be oxidized to spinless charged solitons. The results of the magnetic studies are summarized in Table I. 
TABLE I

SUMMARY OF RESULTS FOR $\left[\mathrm{CH}\left(\mathrm{I}_{3}\right)_{\mathrm{y}}\right]_{\mathrm{x}}$

\begin{tabular}{|c|c|c|c|c|}
\hline Starting $(\mathrm{CH})_{\mathrm{x}}$ & trans & $\underline{\mathrm{cis}}$ & $\underline{\operatorname{trans}}$ & $\underline{\text { cis }}$ \\
\hline y & 0.017 & 0.033 & 0.042 & 0.048 \\
\hline $\mathrm{N}^{\mathrm{C}}, \mathrm{ppmC}$ & 186 & 193 & 110 & 0 \\
\hline $\mathrm{N}\left(\mathrm{E}_{\mathrm{F}}\right)$, states/ev-C & 0.014 & 0.045 & 0.027 & 0.069 \\
\hline$N\left(E_{F}\right)$, states/eV-cm 3 & $7.0 \times 10^{20}$ & $2.3 \times 10^{21}$ & $1.4 \times 10^{21}$ & $3.5 \times 10^{21}$ \\
\hline$\sigma_{\exp }, o_{h m}^{-1} \mathrm{~cm}^{-1}$ & 2.5 & 8 & 20 & 50 \\
\hline $\mathrm{T}_{0}, \mathrm{~K}$ & $1.9 \times 10^{6}$ & $2.9 \times 10^{6}$ & $3.8 \times 10^{5}$ & $4.6 \times 10^{5}$ \\
\hline $\begin{array}{l}\alpha^{-1}, \AA \\
\sigma_{\mathrm{M}}, \mathrm{ohm}^{-1} \mathrm{~cm}^{-1}\end{array}$ & $\begin{array}{l}5.2 \\
2.7 \times 10^{-3}\end{array}$ & $\begin{array}{l}3.1 \\
1.4 \times 10^{-3}\end{array}$ & $\begin{array}{l}7.1 \\
8.8 \times 10^{-2}\end{array}$ & $\begin{array}{l}4.9 \\
8.8 \times 10^{-2}\end{array}$ \\
\hline$\sigma_{\mathrm{CN}}, o \mathrm{hm}^{-1} \mathrm{~cm}^{-1}$ & 1.9 & 9.1 & 3.1 & 12 \\
\hline $\mathrm{R}, \AA$ & 17 & 14 & 13 & 12 \\
\hline $\mathrm{N}^{-1} \mathrm{dN} / \mathrm{dE}, \mathrm{eV}^{-1}$ & 0.46 & 0.42 & 0.60 & 1.9 \\
\hline
\end{tabular}

The results for the two initially trans doped samples show an $N\left(E_{F}\right)$ nearly as low as that reported earlier $/ 11,12 /$ for low susceptibility slow doped samples. The initially cis- $(\mathrm{CH})_{\mathrm{X}}$ samples exhibit a larger $\mathrm{N}\left(\mathrm{E}_{\mathrm{F}}\right)$ then trans- $(\mathrm{CH})_{\mathrm{X}}$ samples doped to the same level. Though $\mathrm{N}\left(\mathrm{E}_{\mathrm{F}}\right)$ for the highly conducting trans doped samples is an order of magnitude down from the expected metaliic level (0.16-0.20 states/eV-C atoms), it is much larger than that of an uncompensated amorphous semiconductor such as amorphous $\mathrm{Si}$ where $\mathbb{N}\left(E_{F}\right) \sim 10^{19}-10^{20}$ state $/ \mathrm{eV}-\mathrm{cm}^{3} / 26 /$.

The $\sigma(295 \mathrm{~K})$ of these samples is reported on Table $I$. The conductivity decreases slowly with decreasing $T$. For each of the nearly metallic samples studied $\sigma(T)$ is best fit by $\sigma(T)=A T^{-1 / 2} \exp \left[-\left(T_{0} / T\right)^{1 / 4}\right]$, as seen in Fig. 3. As $N\left(E_{F}\right)$ is below the metallic value yet very high for a semiconductor, it is tempting to analyze the data in terms of the Mott variable range hopping (vrh) model $/ 26 /$, where $\mathrm{T}_{0}=16 \alpha^{3} /\left(\mathrm{k}_{\mathrm{B}} \mathrm{N}\left(\mathrm{E}_{\mathrm{F}}\right)\right.$ ) and

$$
\alpha T)=0.39\left(\mathrm{~N}\left(\mathrm{E}_{\mathrm{F}}\right) / \alpha \mathrm{k}_{\mathrm{B}} \mathrm{T}\right)^{1 / 2} \nu_{0} \mathrm{e}^{2} \exp \left[-\left(\mathrm{T}_{0} / \mathrm{T}\right)^{1 / 4}\right]
$$

Here $\alpha^{-1}$ is the decay length of a localized state, $\nu_{0}$ is a hopping attempt frequency, and $e$ is the charge per electron. Using $N\left(E_{F}\right)$ and $T_{0}$ for each sample in Table $I, \alpha^{-1}$ is evaluated $\sim 5 \AA$, varying slightly from sample to sample.

Utilizing $N\left(E_{F}\right)$ and $\alpha^{-1}$ from Table $I$ and assuming, as is usually done $/ 26 /$, that $\nu_{0}$ is an optical phonon frequency $/ 24 /\left(\nu_{0}=\nu_{\mathrm{ph}} \sim 3.6 \times 10^{13} \mathrm{sec}^{-1}\right)$, the prefactor in Eq. 1 may be evaluated. The results, evaluated at $295 \mathrm{~K}$ are given in Table $I$ as $\sigma_{M}$. The absolute value of $\sigma$ calculated from $E q .1$ is two to three orders of magnitude too low. This shortcoming of the absolute value of $\sigma(T)$ as calculated in vrh is common, occuring also for amorphous tetrahedral semiconductors such as amorphous Si/26/. Colson and Nagels have suggested/27/ that $\nu_{0}=v_{p h} e^{2 \alpha R}$, where $R$ is the separation between hopping sites. Using $\mathrm{R}$ and $\alpha{ }^{-1}$ from Table I for each $\mathrm{y}$, a corrected $\sigma_{\mathrm{CN}}$ is evaluated. The results for $\mathrm{y}=0.017$ and 0.033 are in very good agreement with experiment. The results for $y=0.048$ and 0.042 are of $f$ by factors of 
4 and 6 respectively, in agreement with their small $\alpha \mathrm{R}$ product implying the impending delocalization. Ohmic behavior for electric fields up to $5 \times 10^{4}$ volts $/ \mathrm{cm}$ at temperatures as low as $8 \mathrm{~K}$ for $\mathrm{y}=0.042$ and 0.048 are in agreement with the expectations of variable range hopping $/ 26 /$.

$S(T)$ may now be examined in the context of these concepts. For vrh $/ 26 /$,

$$
\mathrm{S}^{\mathrm{vrh}}(\mathrm{T})=1 / 2\left(\mathrm{k}_{\mathrm{B}} / \mathrm{e}\right) \mathrm{k}_{\mathrm{B}}\left(\mathrm{T}_{\mathrm{O}} \mathrm{T}\right)^{1 / 2} \mathrm{~N}^{-1} \mathrm{dN} / \mathrm{dE}
$$

while for a metal $/ 26 /$,

$$
S^{m}(T)=\left(2 \pi^{2} / 3\right)\left(k_{B} / e\right) k_{B} N^{-1} d N / d E
$$

where $\mathrm{N}$ is the energy dependent density of states. The best fit of these expressions to the experimental $\mathrm{S}(\mathrm{T})$ is shown in Fig. 4 by the solid lines. Eq. 2 gives a good fit for $\mathrm{y}=0.017$ and $0.033 \mathrm{with} \mathrm{N}-1 \mathrm{dN} / \mathrm{dE}^{-1} 0.4 \mathrm{eV}^{-1}$. That is, $N(E)$ is slowly varying. For $y=0.048, S(T)$ is intermediate between vrh and delocalized (metallic) in behavior. Using Eq. $2, \mathrm{~N}^{-1} \mathrm{dN} / \mathrm{dE}=0.6 \mathrm{eV}^{-1}$. For $\mathrm{y}=0.042, \mathrm{~S}(\mathrm{~T}) \propto \mathrm{T}$ reflecting a nearly delocalized behavior, consistent with the large $\alpha^{-1}$. Using Eq. $3, \mathrm{~N}^{-1} \mathrm{dN} / \mathrm{dE}$ is evaluated as $1.9 \mathrm{ev}^{-1}$. These results are given in Table $I$.

From the optical data presented above, it is suggested that the high density of states in the reduced valence to conduction bandgap may be associated directly with an empty condensate band which persists /25/ at these high doping concentrations. The small values of $\mathrm{N}^{-1}$ ( $\mathrm{dN} / \mathrm{dE}$ ) obtained from vrh analysis of $S(T)$ imply that $E_{F}$ is near the minimum in $N(E)$ between the valence band and condensate band as shown schematically in Fig. 5 . $\mathrm{N}\left(\mathrm{E}_{\mathrm{F}}\right)$ is nonzero due to states being pulled out of the valence and condensate bands by the $I_{3}$ disorder /25/. These states should retain a large soliton-like character /25/. In fact, the effective dimensionally averaged decay length $(\xi)$ of a non interacting soliton, $\xi=\left(\xi_{1}^{2} \xi_{\| 1}\right)^{1 / 3}$, is 3.6 $\AA / 13,15,28 /$ is in good agreement with the $\alpha^{-1}$ values of Table $I$. The larger $a^{-1}$ of 7 . 1Afound for the $y=0.042$ sample reflects the lower $T_{0}$ and is indicative of the near overlap of the solitons at this high density. In this sample vrh must be applied with care as it may be near the transition $125,29 /$ for delocalization and formation of the metallic state.

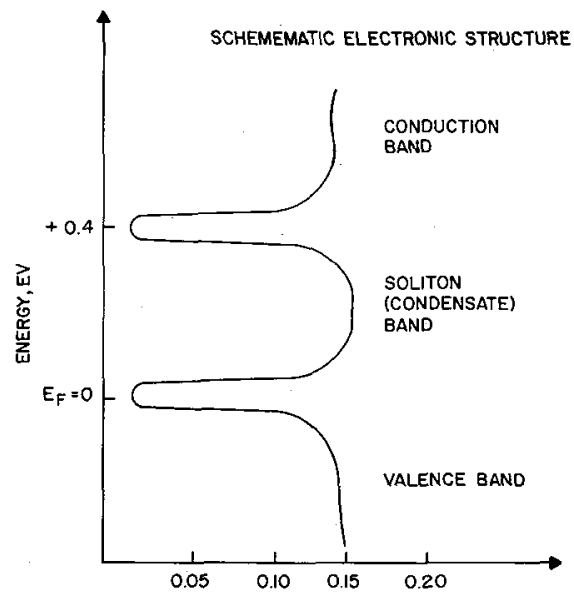

FIGURE 5

Schematic diagram of the electronic structure of nearly metallic polyacetylene

DENSITY OF STATES, STATES/EV-CATOM 
In sum, we have carried out an extensive series of coordinated experiments on $\underline{c}$ is and trans $(\mathrm{CH})_{\mathrm{x}}$ doped to the nearly metallic regime. Results show that the system is composed of a dense array of solitons in the solid. Quantitative analysis of $\sigma(T, E), S(T), X(T)$, optical reflectivity and $X-r a y$ structure is in agreement with a new model of variable range hopping among a dense array of soliton-like states. Trans- $\left(\mathrm{CH}\left(\mathrm{I}_{3}\right)_{y}\right)_{\mathrm{x}}$ has three distinct regimes for charge transport: (a) $\mathrm{y}<0.01$, well fit by intersoliton electron hopping $/ 13,14,15,28 /$, (b) $0.01<\mathrm{y}<0.05$, vrh among soliton-like sites, and (c) y $>0.05$, disordered metallic behavior $/ 19 /$.

This work was supported in part by NSF Solid State Chemistry Grant DMR8218021. The authors acknowledge discussions with P. Robin, J. P. Pouget, R. Comè's and M. J. Rice.

\section{REFERENCES}

1. For recent reviews see Proceedings of the International Conference on Low-Dimensional Conductors, Boulder, CO, Aug. 9-14, 1981, ed. by A.J. Epstein and E. M. Conwell (Mol. Cryst. Liq. Cryst. 77(1981) and $83(1982))$.

2. EPSTEIN, A. J., ROMMELMANN, H. and GIBSON, H. W., Mater. Sci. 7, (1981) 133.

3. RICE, M. J., Phys. Lett. 71A (1979) 152.

4. SU, W. P., SCHRIEFFER, J. R. and HEEGER, A. J., Phys. Rev. Lett. $42(1979) 1698$ and Phys. Rev. B $22(1980) 2099$.

5. BISHOP, A. R., CAMPBELL, D. K. and FESSER, K., Mol. Cryst. Liq. Cryst. T7( 1981$) 253$.

6. BRAZOVSKII, S. A., SOv. Phys. JETP 51(1980)342; BRAZOVSKII, S. A. and KIROVA, N. N., JETP Letters $33(1981) 4$.

7. CHIANG, C. K., EINCHER, JR., C. R., PARK, Y. W., HEEGER, A. J. SHIRAKAWA, H., LOUIS, E. J., GAU, S. C. and MACDIARMID, A. J., Phys. Rev. Lett. 39 (1977) 1098 .

8. FELDBLUM, A., HEEGER, A. J., CHUNG, T. C. and MACDIARMID, A. G., J. Chem. Phys. 77 (1982) 5114 .

9. HOFFMAN, D. M., GIBSON, H. W., EPSTEIN, A. J. and TANNER, D. B., Phys. Rev. B, in press.

10. ROBIN, P., POUGET, J. P., COMES, R., GIBSON, H. W. and EPSTEIN, A. J., these proceedings.

11. EPSTEIN, A. J. ROMMELMANN, H., DRUY, M. A., HEEger, A. J. and MACDIARMID, A. G., Solid State Commun. 38 (1981)683.

12. IKEHATA, S., KAUFER, J., WOERNER, T., PRON, A., DRUY, M. A., SIVAK, A., HEEGER, A. J. and MACDIARMID, A. G., Phys. Rev. Lett. $\underline{45}$ (1980) 1123.

13. EPSTEIN, A. J., ROMMELMANN, H., ABKOWITZ, M. and GIBSON, H. W., Phys. Rev. Lett. $47(1981) 1549$.

14. MOSES, D., DENENSTEIN, A, CHEN, J., HEEGER, A. J., MCANDREW, P., WOERNER, T., MACDIARMID, A. G. and PARK, Y. W., Phys. Rev. B 25 ( 1982$) 7652$.

15. EPSTEIN, A. J., ROMMELMANN, H., ABKOWITZ, M. and GIBSON, H. W., MOl. Cryst. Liq. Cryst. $77(1.981) 81$.

16. SUZUKI, N., OZAKI, M. , ETEMAD, S., HEEGER, A. J. and MACDIARMID, A. G., Phys. Rev. Lett. $\underline{45}(1980) 1209$.

17. SU, W. P., KIVELSON, S. and SCHRIEFFER, J. R., Solid state Sciences $\underline{23}(1981) 201$. 
18. TOMKIEWICZ, Y., SCHULTZ, T.D., BROM, H. B., TARANKO, A. R., CLARKE, T. C. and STREET, G. B., Phys. Rev. B 24 (1981) 4348 .

19. EPSTEIN, A. J., GIBSON, H. W., CHAIKIN, P. M., CLARK, W. G. and GRUNER, G., Phys. Rev. Lett. 45 (1980) 1730 and Chemica Script 17(1981) 135 .

20. ITO, T., SHIRAKAWA, H. and IKEDA, S., J. Polym. Sci. Polym. Chem. Ed. $12(1974) 11 ; 13(1975) 11$.

21. EPSTEIN, A. J., ROMMELMANN, H., FERNQUIST, R., GIBSON, H. W., DRUY, M. A. and WOERNER, T., Polymer $\underline{23}$ (1982) 1211.

22. CUMMINGS, K. D., TANNER, D. B. and MILLER, J. S., Phys. Rev. B $24(1981) 4142$.

23. HSU, S. L., SIGNORELLI, A. J., PEZ, G. P. and BAUGHMAN, R. H., J. Chem. Phys. $69(1978) 106$.

24. FINCHER, JR., C. R., OZAKI, M., HEEGER, A. J. and MACDIARMID, A. G., Phys. Rev. B 19 (1979) 4140; MELE, E. J. and RICE, M. J., Phys. Rev. Lett. 45(1980)926; HOROVITZ, B., Solid State Commun. 41(1982)593 and $\underline{41}(1982) 729$.

25. MELE, E. J. and RICE, M. J., Phys. Rev. B 23 (1981) 5397 .

26. MOTT, N. F. and DAVIS, E. A., Electronic Processes in Non-Crystalline Materials (Clarendon, Oxford, 1979).

27. COLSON, R. and NAGELS, P., J. Noncrystalline Solids $\underline{35}$ (1980) 129.

28. KIVELSON, S., Phys. Rev. B $\underline{25}$ (1980) 3798 .

29. HOFFMAN, D. M., TANNER, D. B., EPSTEIN, A. J. and GIBSON, H. W., Mol. Cryst. Liq. Cryst. 13 (1982) 1175. 